\title{
Investigation of Corrosion Inhibition of Quaternary Ammonium Salt on N80 Steel in 5M HCI Solution
}

\author{
Yang Yaohui ${ }^{1,2, ~ *, ~ L i ~ L i n g j i e ~}{ }^{1,2}$, Zhang Yanjun ${ }^{1,2}$, Lin Zhu ${ }^{1,2}$, Tong Hui ${ }^{1,2}$ \\ ${ }^{1}$ CNPC Research Institute of Engineering Technology, Tianjin, China \\ ${ }^{2}$ Key Laboratory of Tubular Goods Engineering, CNPC-Research Division of Anti-Corrosion Coating and Thermal Insulation Structure, \\ Tianjin, China
}

\author{
Email address: \\ yangyh.cpoe@cnpc.com.cn (Yang Yaohui), lilingj@cnpc.com.cn (Li Lingjie) \\ ${ }^{*}$ Corresponding author
}

\section{To cite this article:}

Yang Yaohui, Li Lingjie, Zhang Yanjun, Lin Zhu, Tong Hui. Investigation of Corrosion Inhibition of Quaternary Ammonium Salt on N80 Steel in 5M HCl Solution. International Journal of Materials Science and Applications. Vol. 6, No. 3, 2017, pp. 160-164. doi: $10.11648 /$ j.ijmsa.20170603.18

Received: April 18, 2017; Accepted: May 19, 2017; Published: June 6, 2017

\begin{abstract}
Corrosion inhibition of $\mathrm{N} 80$ in $5 \mathrm{M} \mathrm{HCl}$ solution by pyridine quaternary ammonium salt has been studied by weight loss measurements, potentiodynamic test, Tafel polarization and electrochemical impedance. The results show that corrosion rates of $\mathrm{N} 80$ steel decrease with increase of inhibitor concentration in $5 \mathrm{M} \mathrm{HCl}$ solution at temperature $333 \mathrm{~K}$ and $363 \mathrm{~K}$. The adsorption of inhibitor on N80 steel was studied from the results of the weight loss experiment. The adsorption is in conformity with langmuir isothermal adsorption equation at $333 \mathrm{~K}$, the value of indicates the adsorption were both chemical and physical adsorption.
\end{abstract}

Keywords: Quaternary Ammonium Salt, Inhibitor, N80 Steel, Corrosion, Absorption

\section{Introduction}

During oil and gas exploitation, acidization is an effective oil well stimulation technique for enhancing oil productivity. Hydrochloric acid is usually used for acidification. Because of the aggressive nature of the acid and high temperature in oil well, severe corrosion attack on tubing and casing may occurred. To reduce the aggressive corrosion of the acid on tubing and casing materials (N80 steel), inhibitors are commonly used during acidization.

Most of corrosion inhibitors are organic compounds containing polar groups (such as, $-\mathrm{NH} 2,-\mathrm{CHO},-\mathrm{COOH},-\mathrm{OH}$, etc.) [1-3] or hetero atoms (such as, N, O, S, P, etc.) [4-6]. corrosions are mitigated since these inhibitors molecules are easily adsorbed on the metals surface, especially $\mathrm{N}$-heterocyclic compounds, as they act by adsorption on the metal surface, and the adsorption of N-heterocyclic inhibitor takes place through nitrogen heteroatom, as well as those with triple or conjugated double bonds or aromatic rings in their molecular structures. It was a corrosion inhibitor with superior property to inhibit the corrosion of steel in acid solution [7-9].
Corrosion inhibition of quaternary ammonium salts on N80 steel in $5 \mathrm{M} \mathrm{HCl}$ solution was investigated by weight loss measurements, potentiodynamic polarization and electrochemical impedance. The steel surface of N80 steel was also examined by scanning electron microscope. Meanwhile, the adsorption thermodynamic parameters and corrosion kinetic parameters were calculated according to adsorption theory and corrosion kinetic formula, based on these parameters, the inhibitive mechanism is discussed.

\section{Experimental}

\subsection{Materialsand Test Solutions}

Quaternary ammonium salts were synthesised from pyridine and Benzyl chloride by quaterisation reaction at $160 \sim 180^{\circ} \mathrm{C}$ for 6 hours with water condensation. The synthetic route and molecular structures were shown in figure 1 . 


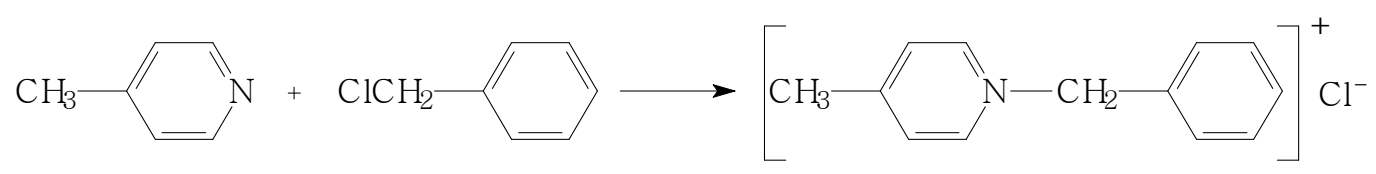

Figure 1. The synthetic route and molecular structure of pyridine quaternary ammonium salt.

Tests were performed on N80 steel specimens with following chemical composition (wt.\%): C0.240, Si 0.220, Mn1.190,P 0.013, S0.004,Cr 0.036, Mo 0.021,Ni 0.028 and Fe balance. The $5 \mathrm{M} \mathrm{HCl}$ solution was prepared by dilution of analytical grade $37 \% \mathrm{HCl}$ with double distilled water.

\subsection{Preparation of Electrodes}

The working electrode was a cylindrical disc cut from an oil well steel (N80). The metal disc was coated with epoxy resin except its bottom surface with area of $1.0 \mathrm{~cm}^{2}$. The surface of working electrode was mechanically abraded using different grades of sand papers, which ended with the 1200 grade. The disc was cleaned by distilled water, ethanol, respectively, finally dried with a filter paper.

\subsection{Weight Loss Study}

The N80 steel specimens used in the weight loss study were cut into desired dimension and the surface preparation was carried out with emery paper grade 600 and 1200, then it was washed with distilled water and acetone and finally dried with cool air. The initial weight of each specimen was noted before immersion using an analytical balance (precision: $\pm 0.1 \mathrm{mg}$ ). Then the specimens were immersed in $5 \mathrm{M} \mathrm{HCl}$ solutions with different concentrations of inhibitors at $333 \mathrm{~K}$ and $363 \mathrm{~K}$ for $4 \mathrm{~h}$ After immersion, the specimens were washed and reweighed.

The inhibition efficiency IE $\%$, surface coverage degree $\theta$ and corrosion rate $V_{\text {corr }}$ were obtained by

$$
\begin{gathered}
\mathrm{IE} \%=\left(W_{0^{-}} W\right) / W_{0} \times 100 \\
\theta=\left(W_{0^{-}} W\right) / W_{0} \\
V_{\text {corr }}=\left(W_{0^{-}}-W\right) / s t
\end{gathered}
$$

$W_{0}$ and $W$ are the weight losses in the absence and presence of the inhibitor, respectively, $s$ is samples surface area, $t$ is immersion time, the unit of $V_{\text {corr }}$ is $\mathrm{mm} \mathrm{y}^{-1}$.

\subsection{Electrochemical Measurements}

The electrochemical experiments were performed with PARSTAT 2273 Potentiostat/Galvanostat in a classical three-electrodes cell with a platinum counter electrode (CE) and a saturated calomel electrode (SCE) coupled to a fine luggin capillary as the reference electrode. The working electrode (WE) was prepared as showed in 2.2. EIS measurement was carried out in $100 \mathrm{kHz}-0.1 \mathrm{~Hz}$ frequency range at open circuit potential (OCP) disturbed with amplitude of $10 \mathrm{mV}$. The potentiodynamic polarization curves were obtained from $-250 \mathrm{mV}$ to $+250 \mathrm{mV}$ (versus OCP) with a scan rate of $0.5 \mathrm{mV} / \mathrm{s}$, the data were collected and analyzed by electrochemical software. The inhibition efficiency for each concentration of inhibitors is calculated by

$$
\mathrm{IE} \%=\left(I_{\text {corr }}-I_{\text {corr(inh) })}\right) / I_{\text {corr }} \times 100
$$

$I_{\text {corr }}$ and $I_{\text {corr(inh) }}$ were the corrosion current density with and without of inhibitors, respectively.

For EIS measurement, IE(\%) was defined as:IE $\%=\left(R_{\mathrm{ct}^{-}}\right.$ $\left.R_{\mathrm{ct}}^{0}\right) / I_{\text {corr }} \times 100(5) R_{\mathrm{ct}}$ and $R_{\mathrm{ct}}^{0}$ were the charge transfer resistance with and without inhibitors, respectively.

\subsection{Surface Analysis}

The surface morphology of the N80 steel samples after immersion in $\mathrm{HCl}$ solution in the presence and absence of the inhibitor, was investigated by using JSM-5600LV scanning electron microscope.

\section{Results and Discussion}

\subsection{Weight Loss Study}

The values of corrosion rates and inhibition eficiencies obtained from the mass loss study for different inhibitor concentrations in $5 \mathrm{M} \mathrm{HCl}$ solution at $333 \mathrm{Kand} 363 \mathrm{~K}$ are summarized in table 1.It was found that the corrosion rates decrease with increase of inhibitor concentration. It is evident from the Table 1 that when the inhibitor concentration is 6.0 $\mathrm{mM}$, the corrosion rates of $\mathrm{N} 80$ steel at $333 \mathrm{~K}$ and $363 \mathrm{~K}$ decreased from $122.77 \mathrm{~mm} / \mathrm{y}$ to $0.920 \mathrm{~mm} / \mathrm{y}$ and from 341.54 $\mathrm{mm} / \mathrm{y}$ to $5.976 \mathrm{~mm} / \mathrm{y}$ respectively, the inhibition efficiencies reaches a maximum value of $99.25 \%$. Table 1 also shows that inhibition efficiency decreases with the experimental temperature, which can be attributed to desorption of inhibitor from the N80 steel surface at the higher temperatures.

Table 1. Corrosion parameters for $\mathrm{N80}$ steel in $5 \mathrm{M} \mathrm{HCl}$ solutions with different concentrations of inhibitors.

\begin{tabular}{llllll}
\hline $\mathbf{T}$ & $\mathbf{C}$ & $\boldsymbol{W}_{\boldsymbol{0}} \boldsymbol{W}$ & $\boldsymbol{V}_{\text {corr }}$ & $\mathbf{I E}$ & $\boldsymbol{\theta}$ \\
$\mathbf{K}$ & $\mathbf{m M}$ & $\mathbf{m g} \cdot \mathbf{c m}-\mathbf{2}$ & $\mathbf{m m} \cdot \mathbf{y}-\mathbf{1}$ & $\mathbf{0}$ & - \\
\hline \multirow{6}{*}{333} & Blank & 43.732 & 122.77 & - & - \\
& 0.02 & 8.304 & 23.315 & 81.01 & 0.8101 \\
& 0.2 & 2.720 & 7.636 & 93.78 & 0.9378 \\
& 0.4 & 1.596 & 4.48 & 96.35 & 0.9635 \\
& 2.0 & 0.695 & 1.952 & 98.41 & 0.9841 \\
& 4.0 & 0.476 & 1.338 & 98.91 & 0.9891 \\
& 6.0 & 0.327 & 0.920 & 99.25 & 0.9925 \\
& Blank & 121.65 & 341.54 & - & - \\
& 0.02 & 28.867 & 81.044 & 76.27 & 0.7627 \\
& 0.2 & 14.573 & 40.914 & 88.02 & 0.8802 \\
363 & 0.4 & 8.211 & 23.053 & 93.25 & 0.9325 \\
& 2.0 & 4.050 & 11.372 & 96.67 & 0.9667 \\
& 4.0 & 2.943 & 8.264 & 97.58 & 0.9758 \\
& 6.0 & 2.128 & 5.976 & 98.25 & 0.9825 \\
\hline
\end{tabular}




\subsection{Scanning Electron Microscopy}
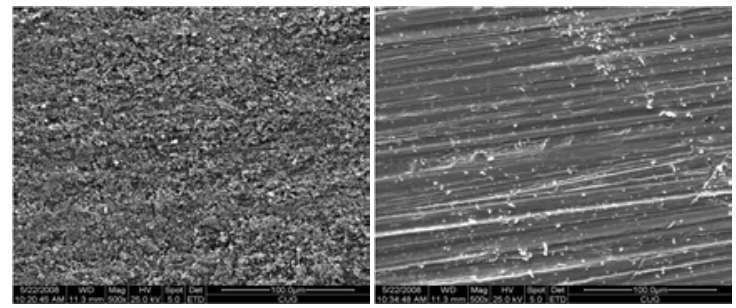

Figure 2. Scanning electron microscopy of of N80 steel samples after immersion in $5 \mathrm{M} \mathrm{HCl}$ (a)without inhibitor (b) with $2.061 \mathrm{mM}$ inhibitor.

Surface examination using SEM (figure 2) was carried out to investigate the effect of inhibitor on the surface morphology of the N80 steel. The surface morphology of the N80 steel specimen after immersion in $5 \mathrm{M} \mathrm{HCl}$ solution at $333 \mathrm{~K}$ with no additives for $4 \mathrm{~h}$ were shown in figure 2(a).The micrograph reveals that the surface was strongly damaged in the absence of inhibitor. The surface morphology of the N80 steel specimen after immersion in $5 \mathrm{M} \mathrm{HCl}$ solution at $333 \mathrm{~K}$ with $2.0 \mathrm{mM}$ of inhibitor was shown in figure 2(b), it can be seen that the rate of corrosion is suppressed in the presence of inhibitors. It is revealed that there is a good protective film adsorbed on specimens surface, which is responsible for the inhibition of corrosion.

\subsection{Potentiodynamic Test}

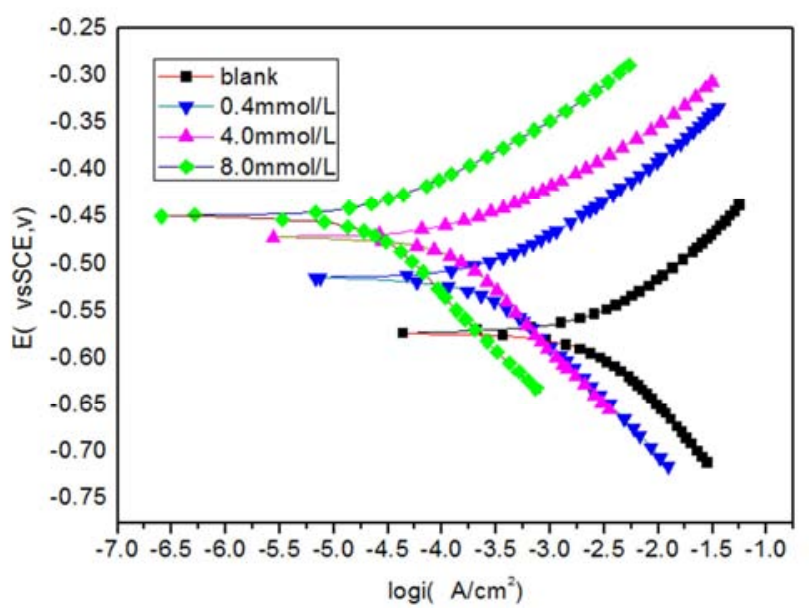

Figure 3. Potentiodynamic curves of $N 80$ steel in $5 \mathrm{M} \mathrm{HCl}$ with different concentrations of inhibitor at $333 \mathrm{~K}$.

The potentiodynamic curves of $\mathrm{N} 80$ steel in $5 \mathrm{M} \mathrm{HCl}$ with different concentrations of inhibitors at $333 \mathrm{~K}$ are shown in figure 3.As seen in figure 3 , anodic and cathodic current decreases with the increasing concentration of corrosion inhibitors, this effect is attributed to the adsorption of the inhibitor on the active sites of the metal surface. The similar shape of anodic and cathodic curves with different concentration of inhibitor indicated that the mechanisms of the cathodic hydrogen reduction and anodic metal dissolving did not change.

Table 2 gives the values of corrosion current, corrosion potential, cathodic and anodic tafel slopes, percentage inhibition efficiency are obtained by the anodic and cathodic regions of the tafel plots. It is obvious from table 2 that the slopes of the cathodic $\left(b_{\mathrm{a}}\right)$ tafel lines remain almost the same with differentconcentration of inhibitor, but the cathodic slope $\left(b_{c}\right)$ increased after addition of inhibitor. The potentiodynamic curves moves in a more anodic direction, the corrosion potential moved about $124 \mathrm{mV}$ (from -573.2 $\mathrm{mV}$ to- $449.4 \mathrm{mV}$ ) with inhibitor concentration increase from $0 \mathrm{mM}$ to $8 \mathrm{mM}$. The positive potential shift and large $b_{\mathrm{c}}$ indicated a mixed type in electrochemical mechanism of this system.

The corrosion current density $I_{\text {corr }}$ reduces from $532.0 \mu \mathrm{A} \cdot \mathrm{cm}^{-2}$ to $7.0 \mu \mathrm{A} \cdot \mathrm{cm}^{-2}$ after addition of inhibitor in $\mathrm{HCl}$ to $8 \mathrm{mM}$, and the inhibition efficiency is as high as $98.7 \%$. It indicates that corrosion rate of $\mathrm{N} 80$ steel in $5 \mathrm{M} \mathrm{HCl}$ decreases and present inhibitive effect.

Table 2. Potentiodynamic parameters of N80 steel in $5 \mathrm{M} \mathrm{HCl}$ with different concentrations of inhibitorat $333 \mathrm{~K}$.

\begin{tabular}{llllll}
\hline $\mathbf{C}$ & $\boldsymbol{E}_{\text {corr }}$ & $\boldsymbol{b}_{\mathbf{c}}$ & $\begin{array}{l}\boldsymbol{b}_{\mathbf{a}} \\
\mathbf{m M} \cdot \mathbf{d e c}^{-\mathbf{1}}\end{array}$ & $\begin{array}{l}\boldsymbol{I}_{\text {corr }} \\
\boldsymbol{\mu A} \mathbf{A} \cdot \mathbf{c m}^{-2}\end{array}$ & $\begin{array}{l}\mathbf{I E} \\
\mathbf{~ \%}\end{array}$ \\
\hline Blank & -573.2 & 75.4 & 54.8 & 532.0 & - \\
0.4 & -514.5 & 90.7 & 55.2 & 52.2 & 90.2 \\
4.0 & -471.2 & 121.2 & 47.6 & 30.4 & 94.3 \\
8.0 & -449.4 & 113.5 & 45.5 & 7.0 & 98.7 \\
\hline
\end{tabular}

\subsection{Electrochemical Impedance}

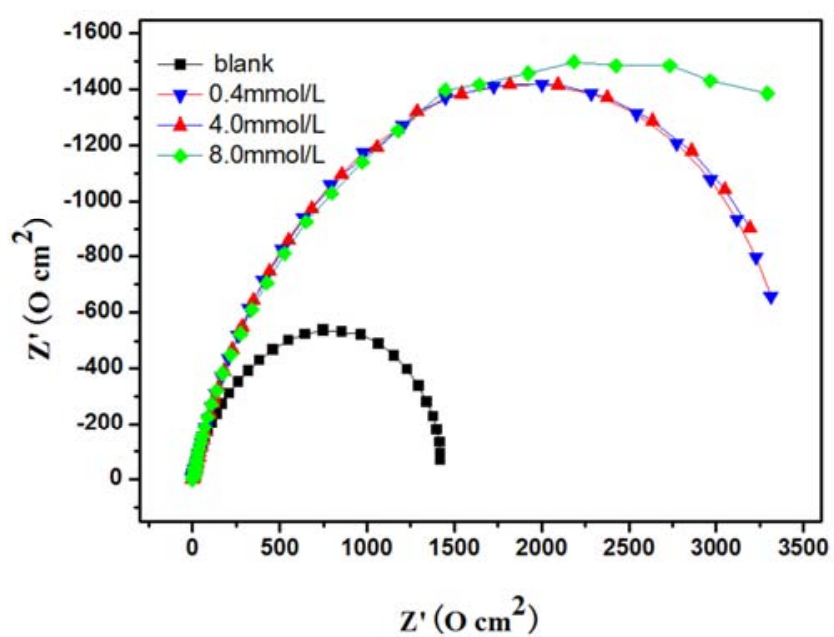

Figure 4. Nyquist diagrams for $\mathrm{N} 80$ steel in $5 \mathrm{~mol} / \mathrm{LHCl}$ with diferent concentrations of inhibitor.

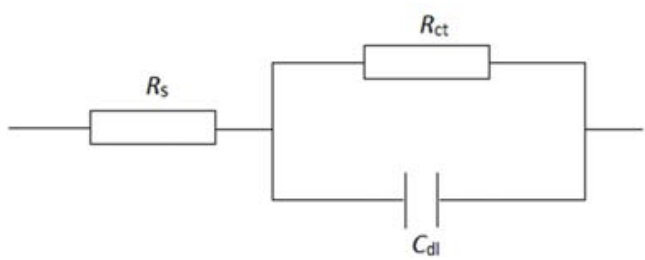

Figure 5. Equivalent circuit fitted for $N 80$ steel in $5 \mathrm{~mol} / \mathrm{LHCl}$ with inhibitor at $333 K$.

Electrochemical impedance measurements were carried over the frequency range from $100 \mathrm{kHz}$ to $0.1 \mathrm{~Hz}$ at open circuit potential. The nyquist representations of impedance 
behaviour of $\mathrm{N} 80$ steel in $5 \mathrm{M} \mathrm{HCl}$ with and without addition of various concentrations of inhibitor are given in figure 4,equivalent circuit fitted for $\mathrm{N} 80$ steel in $5 \mathrm{M} \mathrm{HC1with}$ inhibitor at $333 \mathrm{~K}$ was shown in figure 5,electrochemical impedance parameters and the corresponding inhibition efficiencies, the fitted data was shown in Table $3, R_{\mathrm{s}}, R_{\mathrm{ct}}$ and $C_{\mathrm{dl}}$ were the solution resistance, charge transfer resistance and interfacial double layer capacitance respectively.

Table 3. Electrochemical impedance parameters and the corresponding inhibition eficiencies of $\mathrm{N80}$ steel in $5 \mathrm{M} \mathrm{HCl}$ with diferentconcentrations of inhibitor.

\begin{tabular}{llll}
\hline $\mathbf{C}$ & $\boldsymbol{R}_{\mathbf{c t}}$ & $\boldsymbol{C}_{\mathbf{d l}}$ & $\mathbf{I E}$ \\
$\mathbf{m M}$ & $\boldsymbol{\Omega} \cdot \mathbf{c m}^{2}$ & $\boldsymbol{\mu} \mathbf{F} \cdot \mathbf{c m}^{-2}$ & $\boldsymbol{\%}$ \\
\hline Blank & 461 & 620.20 & - \\
0.4 & 3770 & 475.14 & 87.8 \\
4.0 & 3886 & 364.32 & 88.1 \\
8.0 & 4658 & 290.67 & 90.1 \\
\hline
\end{tabular}

It is seen that addition of inhibitor increases the values of $R_{\mathrm{ct}}$ and reduces the $C_{\mathrm{dl}}$. The decrease in $C_{\mathrm{dl}}$ is attributed to increase in thickness of electronic double layer [10]. The increase in $R_{\mathrm{ct}}$ value is attributed to the formation of protective film on the metal/solution interface [11-12]. The EIS diagrams confirm the higher protection with increasing the concentration of the inhibitor, which is related to adsorption of the inhibitor on the metal surface.

\subsection{Adsorption Isotherm and Thermodynamic Parameter}

The adsorption of surfactants at metal/solution interfaces can markedly change the corrosion resisting properties of metals. The efficiency of corrosion inhibitors mainly depends on their adsorption ability on the metal surface, so, it is essential to know the mode of adsorption and the adsorption isotherm of corrosion inhibitors.

The surface coverage values are evaluated using corrosion rate values obtained from the weight loss method. Attempts were made to fit the $\theta$ values to various isotherms, including Langmuir, Frumkin and Temkin isotherm. By far, the best fit is obtained with the Langmuir isotherm. Langmuir adsorption isotherm is described by the following equations:

$$
C_{\text {inh }} / \theta=C_{\text {inh }}+1 / K_{a d s}
$$

Where $C_{\text {inh }}$ is inhibitor concentration, $\theta$ is the degree of the coverage on the metal surface and $K_{\text {ads }}$ is the equilibrium constant for the adsorption-desorption process.

In order to clarify the nature and the strength of adsorption, the experimental results have been fitted on the assumption that the adsorption isotherm of corrosion inhibitors corresponds to the form of langmuir isotherm, the results of data fitting is presented graphically in figure 6.The correlation coefficient $\left(\mathrm{R}^{2}=0.9999\right)$ is close to one confirm this assumption. The average value of $K_{\text {ads }}$ have been found to be $5.99 \times 10^{4} \mathrm{M}^{-1}$ indicating that the adsorbed inhibitor molecules form monolayer on the mild steel surface and there is no interaction among the adsorbed inhibitor molecules [13]. The standard free energy of adsorption $\left({ }^{\circ} G_{\mathrm{ad}}^{0}\right)$ values of inhibitors are obtained from the following equation and the value of $\Delta$
$G_{\text {ads }}^{0}$ is calculated as- $34.07 \mathrm{~kJ} \mathrm{~mol}^{-1}$ at $333 \mathrm{~K}$.

$$
\triangle G_{a d s}^{0}=-R T \ln \left(55.5 K_{\text {ads }}\right)
$$

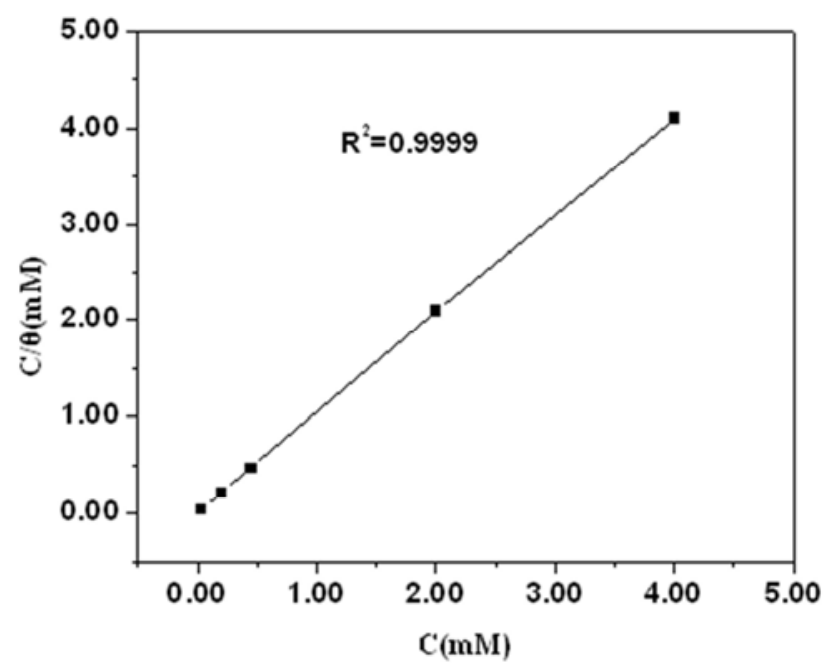

Figure 6. Langmiur adsorption plots of $N 80$ steel in $5 \mathrm{M} \mathrm{HCl}$ with diferent concentrations of inhibitor at $333 \mathrm{~K}$.

Generally the negative values of standard free energy of adsorption indicate spontaneous adsorption of inhibitor on mild steel surface. The standard free energy of adsorption values of $-20 \mathrm{~kJ} \mathrm{~mol}^{-1}$ or less negative are associated with physical adsorption of inhibitor, if the value is- $40 \mathrm{~kJ} \mathrm{~mol}^{-1}$ or more negative, it indicated that the adsorption of inhibitor on the steel surface is chemical adsorption [14-15]. The values of standard free energy of adsorption are between $-20 \mathrm{~kJ}$ $\mathrm{mol}^{-1}$ and $-40 \mathrm{~kJ} \mathrm{~mol}^{-1}$, it can be concluded that the adsorption takes place through both chemical and physical adsorption [16].

\section{Conclusion}

Weight loss study showed that the inhibition efficiency of quaternary ammonium salt increases with increase in inhibitor concentration, the inhibition efficiencies reaches a maximum value of $99.25 \%$. Potentiodynamic polarization proved that quaternary ammonium salt is an efficient corrosion inhibitor having mixed type of inhibition property. Electrochemical impedance showed that addition of inhibitor increases the values of $R_{\mathrm{ct}}$ and reduces the $C_{\mathrm{dl}}$ on account of the formation of protective film on the metal/solution interface. The adsorption of inhibitor on N80 is in conformity with langmuir isothermal adsorption equation at $333 \mathrm{~K}$, the value of $\Delta G_{a \downarrow s}^{0}$ indicates the adsorption were both chemical and physical adsorption.

\section{References}

[1] S. M. A. Hosseini, A. Azimi, The inhibition of mild steel corrosion in acidicmedium by

1-methyl-3-pyridin-2-yl-thiourea, Corros. Sci. 51 (2009) 728-732. 
[2] M. Behpour, S. M. Ghoreishi, N. Mohammadi, N. Soltani, M. Salavati-Niasari.Investigation of some Schiff base compounds containing disulfide bond as $\mathrm{HCl}$ corrosion inhibitors for mild steel Corros. Sci. 52 (2010) 4046-4057.

[3] Sudhish Kumar Shukla, M. A. Quraishi. The effects of pharmaceutically active compound doxycycline on the corrosion of mild steel in hydrochloric acid solution. Corros. Sci. 52 (2010) 314-321.

[4] M. Lagrenee, B. Mernari, M. Bouanis, M. Traisnel, F. Bentiss, Corros. Sci. 44(2002) 573-588.

[5] M. A. Quraishi, I. Ahamad, A. K. Singh, S. K. Shukla, B. Lal, V. Singh, Matar. Chem. Phys. 112 (2008) 1035-1039.

[6] M. Behpour, S. M. Ghoreishi, N. Mohammadi, N. Soltani b, M. Salavati-Niasari,Investigation of some Schiff base compounds containing disulfide bond as $\mathrm{HCl}$ corrosion inhibitors for mild steel, Corros. Sci 52 (2010) 4046-4057.

[7] F. Bentiss, M. Traisnel, L. Gengembre, M. Lagrenee, Inhibition of acidic corrosion of mild steel by 3,5-diphenyl-4H-1,2,4-triazole, Appl. Surf. Sci. 161 (2000) 194-202.

[8] J. Cruz, R. Martinez, J. Genesca, E. García-Ochoa, Experimental and theoretical study of 1-(2-ethylamino)-2-methylimidazoline as an inhibitor of carbon steel corrosion in acid media, J. Electroanal. Chem. 566 (2004) 111-121.
[9] L. Wang, Inhibition of mild steel corrosion in phosphoric acid solution by triazole derivatives, Corros. Sci. 48 (2006) 608-616.

[10] M. G. Hosseini, M. Ehteshamzadeh, T. Shahrabi, Electrochem. Acta 52 (2007) 3680-3685.

[11] F. Bentiss, M. Traisnel, M. Lagrenee, Corros. Sci. 42 (2000) 127-146.

[12] S. Murlidharan, K. L. N. Phani, S. Pitchumani, S. Ravichandran, J. Electrochem. Soc. 142 (1995) 1478-1483.

[13] E. E. Ebenso, I. B. Obot, L. C. Murulana, Quinoline and its derivatives as effective corrosion inhibitors for mild steel in acidic medium, Int. J. Electrochem. Sci. 5 (2010) 1574-1586.

[14] F. Bentiss, M. Lebrini, M. Lagrenée, Thermodynamic characterization of metal dissolution and inhibitor adsorption processes in mild steel/2,5-bis(n-thienyl)-1,3,4-thiadiazoles/ hydrochloricacid system, Corros. Sci. 47 (2005) 2915-2931.

[15] X. Li, S. Deng, H. Fu, Triazolyl blue tetrazolium bromide as a novel corrosion inhibitor for steel in $\mathrm{HCl}$ and $\mathrm{H} 2 \mathrm{SO} 4$ solutions, Corros. Sci. 53 (2011) 302-309.

[16] M. Hosseini, S. F. L. Mertens, M. R. Arshadi, Corros. Sci. 45 (2003) 1473. 